\title{
CRESCIMENTO EM VIVEIRO DE CULTIVO DO CAMARÃO CANELA (MAC'ROBRACHIUM AMAZONICUM) (DECAPODA, PALAEMONIDAE)
}

\author{
PETRONIO ALVES COELHO \\ MARILENA RAMOS-PORTO2 \\ ALINE DO VALE BARRETO \\ VANDETE ELIAS DA COSTA*
}

ABSTRACT

Prawn growth in intensive culture ponds depends upon the cultured species and internal (nutrition state) and external (pond condition) factors. To obtain growth taxa in aquaculture for the "canela" prawn (Macrobrachium amazonicum), experiments were carried out at Amapá and Pernambuco, Brazil. The initial prawn population of Amapá ponds came from different places of the Amazon river, while those from Pernambuco from hatcheries of the Departamento de Oceanografia da Universidade Federal de Pernambuco. Physicochemical and biological analyses of the water were made at the same time. The growth rate was estimated through collections of samples of about $10 \%$ of the initial population, with measures of the orbital length of each individual. Ponds' harvests were done when most of the population presented an orbital length equal to or larger than $80 \mathrm{~mm}$. The present results showed $70 \mathrm{~mm}$ average size after 3-4 months of the post-larvae settlement to be the ideal for harvesting, favouring the utilization of this species for intensive aquaculture. Data on correlation, orbital and total growth, and weight gain were obtained during prawn growth.

\section{INTRODUÇÃO}

Vários estudos têm sido realizados sobre o crescimento de camarões do gênero Macrobrachium. Nestes estudos tem sido levada em conta a influência de vários fatores, como a alimentação (Balazs et al., 1974; Manik, 1976; Sandifer \& Joseph, 1976; Willis, Hagood \& Ellason, 1976; Coelho, Ramos-Porto \& Cordeiro, 1978a, b), a densidade de população (Sandifer \& Smith, 1975; Willis, Hagood \& Ellason, 1976; Willis \& Berrigan, 1977), as condições da água tais como: temperatura, salinidade e teor de oxigênio (Perdue \& Nakamura, 1976; Coelho et al., 1978; Farmanfarmaian \& Moore, 1978). Em alguns estudos realizados é possível comparar o crescimento de duas espécies como $M$. acanthurus e $M$. rosenbergii (Willis, Hagood \& Ellason, 1976), $M$. acanthurus e $M$. carcinus (Coelho et al., 1978) e $M$. carcinus e $M$. rosenbergii (Coelho \& Correia, 1980).

Poucos destes estudos, no entanto, foram realizados em cultivos de campo. Porém, de sua análise resulta que o crescimento depende da estação considerada, das condições do cultivo (alimentação, densidade de povoamento e qualidade da água).

Com relação a $M$. amazonicum, especificamente, é conhecido trabalho anterior de Guest (1979), cujos resultados são de grande interesse.

$\mathrm{Na}$ presente pesquisa procura-se determinar o crescimento do camarão M. amazonicum, levando em consideração a densidade de povoamento em condições de cultivo intensivo em viveiros no campo.

\section{MATERIAL E METODOS}

Os camarões foram cultivados em 10 viveiros experimentais, 7 localizados no Território Federal do Amapá e 3 em Pernambuco. Os viveiros do Amapá

1. Departamento de Oceanografia, Universidade Federal de Pernambuco.

2. Departamento de Pesca, Universidade Federal Rural de Pernambuco.

3. Pesquisadora Assistente da Financiadora de Estudos e Projetos (FINEP).

4. Departamento de Recursos Naturais, Divisão de Recursos Pesqueiros, Superintendência de Desenvolvimento do Nordeste. 
eram abastecidos com água proveniente do Rio Amazonas, possuíam cerca de $80 \mathrm{~m}^{2}$ de superfície e profundidade máxima de 1,80 m, tendo sido escavados no solo; estes viveiros situavam-se na localidade Vila Amazonas, Município de Macapá. Em Pernambuco, foram utilizados 3 viveiros, um com cerca de $1000 \mathrm{~m}^{2}$ de superfície, escavado no solo, e dois de $40 \mathrm{~m}^{2}$ de superfície, totalmente revestidos de cimento, porém com fundo artificial de terra; estes viveiros situavam-se, o primeiro em Dois Irmãos e os demais em Cordeiro, Município do Recife. Os viveiros localizados no DPA eram alimentados com água proveniente de poço artesiano, tendo estes viveiros uma profundidade de $80 \mathrm{~cm}$.

Os camarões destinados ao povoamento inicial dos viveiros no Amapá, foram capturados nas margens do Rio Amazonas, mais precisamente nas Ilhas do Maraim, Chagas e Santana. Os empregados no povoamento dos viveiros em Pernambuco de criações de larvas realizadas no Departamento de Oceanografia.

No Amapá, foi observada quotidianamente, em cada viveiro, a temperatura às 08,13 e $17 \mathrm{~h}$, e a transparência às $09 \mathrm{~h}$; além disto, semanalmente, foi realizada a determinação dos teores de cloro, nitrito, fosfato, silicato, dureza e $\mathrm{pH}$ da água de um dos viveiros.

Em Pernambuco, foi realizada mensalmente a determinação dos teores de nitrito, nitrato, fosfato, $\mathrm{pH}$, oxigênio e transparência da água.

Para a determinação do crescimento foram realizadas biometrias, consistindo essencialmente no recolhimento de uma amostra equivalente a cerca de $10 \%$ da população, na determinação do comprimento orbital de cada indivíduo presente na amostra, anotando, quando for o caso, a presença de fêmeas ovadas ou desovadas, de camarões parasitados e camarões moles e na determinação do peso, em gramas do amostra. Por comprimento orbital se entende a distância em $\mathrm{mm}$, desde a margem posterior da cavidade orbital até a extremidade posterior do telson.

Diariamente foi fornecida alimentação artificial aos camarões, na quantidade de $5 \%$ do peso da população de cada viveiro.

Os viveiros foram despescados quando uma fração importante da população atingia o comprimento orbital de $80 \mathrm{~mm}$, exceto no caso do viveiro 3 , despescado por ter havido início de mortandade epidêmica.

Os dados de povoamento e despesca dos viveiros estão indicados na Tabela 1.

TABELA I - Dados de povoamento e despesca dos viveiros.

\begin{tabular}{ccccc}
\hline VIVEIRO & NQ DE CAMAROES & POVOAMENTO & DESPESCAS & $\begin{array}{c}\text { DURAÇA DO CULTIVO } \\
\text { (MESES) }\end{array}$ \\
\hline Amapá & & & & \\
1 & 500 & $02 / 02 / 80$ & $29 / 05 / 80$ & 4,0 \\
2 & 1.000 & $03 / 02 / 80$ & $29 / 10 / 80$ & 9,0 \\
3 & 1.500 & $09 / 02 / 80$ & $10 / 07 / 80$ & 4.0 \\
4 & 500 & $12 / 02 / 80$ & $29 / 05 / 80$ & 3,5 \\
5 & 500 & $13 / 02 / 80$ & $29 / 08 / 80$ & 6,5 \\
6 & 1.000 & $18 / 02 / 80$ & $29 / 08 / 80$ & 6,5 \\
7 & 1.500 & $27 / 02 / 80$ & $29 / 10 / 80$ & 8,0 \\
Pernambuco & & & & 6,0 \\
A & 600 & $02 / 04 / 81$ & $30 / 10 / 81$ & 6,0 \\
B & 558 & $02 / 04 / 81$ & $30 / 10 / 81$ & 4,0 \\
\hline C & 1.200 & $12 / 05 / 81$ & $09 / 09 / 81$ & 6.0 \\
\hline
\end{tabular}


No momento da despesca, foram utilizados alguns exemplares para determinar as relações entre os comprimentos orbital, total e da carapaça, assim como entre o comprimento orbital e o peso do abdômen.

\section{RESULTADOS}

Nos cultivos realizados no Amapá, a temperatura da água mostrou correlação com a do ar. Esta apresentou pequena variação: os valores médios de $23,5^{\circ} \mathrm{C}$ (março) a $27,1^{\circ} \mathrm{C}$ (setembro e outubro) às $08 \mathrm{~h}$, se elevam rapidamente para $27,9^{\circ} \mathrm{C}$ (março) a $32,5^{\circ} \mathrm{C}$ (setembro) às $13 \mathrm{~h}$, caindo a seguir para $27,6^{\circ} \mathrm{C}$ (março) a $30,8^{\circ} \mathrm{C}$ (setembro) às $17 \mathrm{~h}$. Assim sendo, a temperatura da água dos viveiros não podia deixar de ser elevada; em março, em média, a temperatura passou de $27,4^{\circ} \mathrm{C}$ às $08 \mathrm{~h}$ para $28,0^{\circ} \mathrm{C}$ às $13 \mathrm{~h}$, caindo para $27,6^{\circ} \mathrm{C}$ às $17 \mathrm{~h}$, e em setembro, de $27,0^{\circ} \mathrm{C}$ às $07 \mathrm{~h}$, para $28,5^{\circ} \mathrm{C}$ às $13 \mathrm{~h}$, caindo para $28,7^{\circ} \mathrm{C}$ às $17 \mathrm{~h}$. As diferenças de temperatura da água entre os viveiros eram insignificantes. O sistema de filtração empregado não conseguia diminuir a grande turbidez da água dos viveiros; graças à quantidade de material em suspensão, a transparência, embora tenha aumentado ao longo do cultivo, sempre foi tão pequena que impediu quase totalmente a fixação de algas além de 1-1,2 $\mathrm{m}$ de profundidade. Os teores de cloro, nitrito e fosfato da água sempre foram muito baixos ou nulos; o teor de silicato sempre foi elevado, podendo atingir, por vezes, $30 \mathrm{ppm}$; nestas condições a dureza total variou entre $1^{\circ}$ e $2^{\circ}$, classificando a água como "muito mole". $\mathrm{O} \mathrm{pH}$, no entanto, variou entre 6,8 e 7,1 .

Em Pernambuco, a transparência da água nos viveiros $\mathrm{A}, \mathrm{B}$ e C diminuiu ao longo do cultivo. Os teores de nitrito e nitrato também diminuíram nos viveiros $\mathrm{A}$ e $\mathrm{B}$ e oscilou no viveiro $\mathrm{C}$. Neste último, o fosfato aumentou progressivamente durante o cultivo. Enquanto no "A" estes teores decresceram, no " $\mathrm{B}$ " permaneceram altos ao longo de todo o cultivo. $\mathrm{O} \mathrm{pH}$ dos viveiros $A$ e $B$ apresentaram um valor variando entre 7,15 a 8,0 , enquanto no "C" este valor oscilou entre 7,20 a 8,0 .

Os dados sobre o crescimento dos camarões no Amapá estão resumidos na Tabela II. É possível observar que o crescimento médio é inversamente

\begin{tabular}{|c|c|c|c|}
\hline \multirow{2}{*}{$\begin{array}{l}\text { DURACGAO DO CUL } \\
\text { TIVO (MESES) }\end{array}$} & \multicolumn{3}{|c|}{ DENSIDADE INICIAL DE POVOAMENTO } \\
\hline & 6,25 & 12,5 & 18,75 \\
\hline 0 & 36 & 38 & 36 \\
\hline 1,0 & - & - & 43 \\
\hline 1,5 & 53 & 49 & 47 \\
\hline 2,0 & 49 & 48 & - \\
\hline 3,0 & - & - & 53 \\
\hline 3,5 & 69 & 63 & 55 \\
\hline 4,0 & 73 & 58 & 54 \\
\hline 6,0 & - & - & 63 \\
\hline 6,5 & 79 & 71 & - \\
\hline 7,0 & - & 69 & - \\
\hline 8,0 & - & - & 70 \\
\hline 9,0 & - & 74 & - \\
\hline
\end{tabular}


proporcional à densidade inicial do povoamento. Assim, considerando o tamanho de povoamento de $35-40 \mathrm{~mm}$, o tamanho médio de $70 \mathrm{~mm}$, ideal para a despesea, foi atingido em apenas 3,5-4 meses nos viveiros com densidade inicial de 6,25 camarões por $\mathrm{m}^{2}$, porém em 6-7 meses nos viveiros com densidade inicial de 12,5 e em 8 meses nos viveiros com densidade inicial de 18,75 .

Em Pernambuco, os dados sobre crescimento (Tabela III) indicam que o comprimento médio de $70 \mathrm{~mm}$, considerado ideal para despesca, foi conseguido em apenas 4 meses no viveiro com densidade de 1,2 camarões por $\mathrm{m}^{2}$, porém em 6 meses nos viveiros com 15 camarões por $\mathrm{m}^{2}$ e 13,95 camarões por $\mathrm{m}^{2}$; sendo $62,8 \mathrm{~mm}$ o comprimento médio dos camarões nos viveiros " $\mathrm{A}$ " $\mathrm{e}$ " $\mathrm{B}$ " e de $74,5 \mathrm{~mm}$ no viveiro "C". Convém salientar que o comprimento médio no dia do povoamento foi de 7,0 mm nos viveiros " $A$ " e " $B$ " e de 7,3 mm no viveiro " $\mathrm{C}$ ".

TABELA 111 - Crescimento mếdio dos camarōes nos viveiros de cult ț

vo do DPA - Recife.

\begin{tabular}{|c|c|c|c|c|}
\hline \multirow{2}{*}{\multicolumn{2}{|c|}{$\begin{array}{l}\text { DURACCAO DO CUL } \\
\text { TIVO (MESES) }\end{array}$}} & \multicolumn{3}{|c|}{ DENSIDADE INICIAL DE POYOAMENTD } \\
\hline & & 1,2 & 13,95 & 15 \\
\hline & 0 & 7 & 7 & 7 \\
\hline & 1 & - & 27 & 25 \\
\hline & 2 & 58 & 37 & 39 \\
\hline & 3 & 64 & 47 & 48 \\
\hline & 4 & 75 & 48 & 49 \\
\hline & 5 & - & 55 & 54 \\
\hline & 6 & - & 63 & 63 \\
\hline
\end{tabular}

Outro aspecto importante do crescimento está no aumento do peso. Apesar das imprecisões inevitáveis em trabalho de campo, foi possível calcular, a partir dos dados das biometrias, os seguintes valores aproximados:

Comprimento total $(\mathrm{mm})$

40

50

60

70

80
Peso médio $(\mathrm{g})$

1,2

2,4

4,4

7,0

12,5

Agrupando os camarōes por classes de comprimento, foi possível calcular:

Classes de comprimento $(\mathrm{mm}) \quad$ Peso médio total $(\mathrm{g})$

Abdômen

41-60

2,5

61-80

7,0

81.100

15,5

1,0

4,0

7,0

As relações entre as medidas de comprimento, determinadas a partir das biometrias, foram as seguintes:

a) c.t. $=1,35$ c.o.

b) c.c. $=0,46$ c.t. (c.o. entre 41 e $80 \mathrm{~mm}$ )

c) c.c. $=0,49$ c.t. (c.o. entre 81 e $100 \mathrm{~mm}$ ). 


\section{CONCLUSOEES}

Em vista de o camarão canela, Macrobrachium amazonicum, apresentar um tamanho médio de $70 \mathrm{~mm}$, considerado ideal para a despesca, num prazo de 3 a 4 meses em cultivo intensivo, torna-se favorável sua criação em larga escala.

A duração do cultivo está correlacionado com a densidade de povoamento, portanto quanto menor a densidade maior a taxa de crescimento, o peso e a sobrevivência.

\section{REFERENCIAS}

Balazs, G. H., S. E. Olbrich \& M. E. Tumbleson, 1974. Serum constituents of the Malaysian prawn Macrobrachium rosenbergii and pink shrimp Penaeus marginatus. Aquaculture, Amst. 3: 147-157.

Balazs, G. H., E. Ross, C. C. Brooks \& T. Fujimura, 1974. Effects of protein source and level on growth of the captive freshwater prawn, Macrobrachium rosenbergii. Proc. A. Mtg Wld Maricult. Soc. 5: 1-4.

Coelho, P. A. et al., 1978. Estudo da tecnologia adequada para carcinocultura em água doce. III. Influência dos fatores ambientais sobre a viabilidade do cultivo dos camarões Macrobrachium acanthurus e M. carcinus. Res. Simp. bras. Aquicult., Recife 1: 58-59.

Coelho, P. A. \& E. S. Correia, 1980. Estudo comparativo do crescimento de Macrobrachium carcinus e $M$. rosenbergii criados em viveiro. Ciênc. Cult., $S$ Paulo 32(7): 835.

Coelho, P. A., M. Ramos-Porto \& E. A. Cordeiro, 1978. Influência da alimentação sobre o crescimento de camarões do gênero Macrobrachium (Crustacea, Decapoda, Palaemonidae): Resultados preliminares. Ibid. 30(7): 558.

Coelho, P. A., M.Ramos-Porto \& A. C. M. Beltrão, 1978. Estudo da tecnologia adequada para carcinocultura em água doce. II. Comportamento dos camarões Macrobrachium acanthurus, M. carcinus: Resultados preliminares. Res. Simp. bras. Aquicult., Recife 1: 57.

Farmanfarmaian, A. \& R. Moore, 1978. Diseasonal thermal aquaculture. 1. Effect of temperature and dissolved oxygen on survival and growth of Macrobrachium rosenbergii. Proc. A. Mtg Wld Maricult. Soc. 9 (Atlanta, Ga.): 3-6.

Guest, W. C., 1979. Laboratory life history of the palaemonid shrimp Macrobrachium amazonicum (Heller) (Decapoda, Palaemonidae). Crustaceana 57(2): 141-152.

Manik, R., 1976. Preliminary studies on the effect of different pelletized formulated feeds on the growth of Macrobrachium rosenbergii. Bull. Shrimp Cult. Res. Cont. 2(1-2): 187-193.

Perdue, J. A. \& R. Nakamura, 1976. The effect of salinity in the growth of Macrobrachium rosenbergii. Proc. A. Mtg Wld Maricult. Soc. 7: 647-654.

Sandifer, P. A. \& J. D. Joseph, 1976. Growth responses and fatty acid composition of juvenile prawns (Macrobrachium rosenbergii) fed a prepared ration augmented with shrimp head oil. Aquaculture, Amst. 8(2): 129-138.

Sandifer, P. A. \& T. I. J. Smith, 1975. Effects of population density on growth and survival of Macrobrachium rosenbergii reared in recirculating water management systems. Proc. A. Mtg Wld Maricult. Soc. 6: 43-54.

Willis, S. A., R. W. Hagood \& G. T. Ellason, 1976. Effects of four stocking densities and three diets on growth and survival of post-larvae Macrobrachium rosenbergii and $M$. acanthurus. Ibid. 7: 655-665.

Willis, S. A. \& M. E. Berrigan, 1977. Effects of stocking size and censity on growth and survival of Macrobrachium rosenbergii de Man in ponds. Ibid. 8 (San José, C. R.): 251-264. 